\title{
Characterization of 'Gala' Apple Aroma and Flavor: Differences between Controlled Atmosphere and Air Storage
}

\author{
Anne Plotto ${ }^{1}$ and Mina R. McDaniel ${ }^{2}$ \\ Department of Food Science and Technology, Oregon State University, Corvallis, OR 97331 \\ James P. Mattheis ${ }^{3}$ \\ U.S. Department of Agriculture, Tree Fruit Research Center, 1104 North Western Avenue Wenatchee, \\ WA 98001
}

\begin{abstract}
AdDitional IndeX words. Malus sylvestris var. domestica, quality, volatiles, controlled atmosphere, esters, titratable acidity, soluble solids concentration

Abstract. Aroma and flavor characters of 'Gala' apples [Malus sylvestris (L.) Mill. var. domestica (Borkh.) Mansf. 'Gala'] were identified by 10 trained panelists. A vocabulary of 13 aroma descriptors and 16 flavor descriptors were used to characterize changes in controlled atmosphere (CA) and air, or regular atmosphere (RA) storage over 20 weeks. When compared with RA storage, the intensity of fruity (pear, banana, and strawberry) and floral descriptors decreased after 10 weeks in CA for whole and cut fruit aroma and flavor. During the entire storage period under CA, aroma of cut apples retained high vegetative and citrus characters but had a less intense anise aroma. Sourness and astringency were significantly higher for CA-stored apples, and sweetness was significantly lower. A musty note was perceived in whole apples stored in CA for 20 weeks. Aroma of whole fruit stored for 16 weeks in CA followed by 4 weeks in RA was higher in fruitiness, banana, floral, and anise characters when compared with apples stored 20 weeks in CA. There was no difference between fruit stored in CA followed by RA versus CA stored apples for flavor and aroma of cut fruit. Changes in descriptor ratings during storage are discussed in relation to gas chromatography and olfactometry data obtained with the Osme method.
\end{abstract}

Consumer opinion determines the success or failure of new products (Williams, 1981). Typically, consumers are vague and not consistent in the vocabulary they use to explain their acceptance or rejection of a product (Williams and Knee, 1977). Through descriptive sensory analysis (DSA), product characteristics are identified and variations are measured by trained panelists. Changes in some attributes may explain consumer acceptance of or preference for a product (Williams and Knee, 1977). Instrumental measurements may then be used to understand the physicochemical stimuli necessary to induce a response from the sensory receptors.

Williams and collaborators have used all three approaches (DSA, consumer tests, and instrumental analysis) to understand the quality of apples (Malus sylvestris var. domestica, 'Cox's Orange Pippin'). They developed a lexicon with 95 descriptive terms (Williams and Carter, 1977). Then, aroma descriptors were correlated with gas chromatographic data (Williams and Knee, 1977). DSA data for 'Cox's Orange Pippin' were also used to interpret a consumer survey where panelists were asked to rate acceptability of apples that had been stored under different atmospheres and temperatures (Williams and Langron, 1983). Following those studies, Williams (1979) identified texture to be important for consumer acceptance. When optimum texture was present in apples, consumer preference was increased by better aroma and flavor.

Controlled atmosphere (CA) storage is used commercially to prolong apple shelf life. While low $\mathrm{O}_{2}$ and high $\mathrm{CO}_{2}$ significantly reduce acidity and firmness loss (Smock, 1979), volatile production

Received for publication 24 Aug. 1998. Accepted for publication 10 Apr. 1999. Joint publication of the Oregon Agricultural Experiment Station and the U.S. Department of Agriculture-Agricultural Research Service. This research was funded by the Washington Tree Fruit Research Commission and the Oregon Agricultural Experiment Station. The cost of publishing this paper was defrayed in part by the payment of page charges. Under postal regulations, this paper therefore must be hereby marked advertisement solely to indicate this fact.

${ }^{1}$ Graduate research assistant.

${ }^{2}$ Professor.

${ }^{3}$ Research scientist. is negatively affected (Patterson et al., 1974). A consumer panel preferred the texture of CA-stored 'Cox's Orange Pippin' apples but found those apples had poor aroma and flavor compared with apples stored in air, or regular atmosphere (RA) (Williams and Langron, 1983). Other studies comparing CA with RA-stored fruit found similar differences in firmness, tartness, aroma and flavor descriptors (Anderson and Penney, 1973; Smith, 1984). CA-stored apples are generally preferred to RA-stored fruit. Changes in firmness and volatile production during CA storage vary with factors such as atmosphere composition, apple cultivar, and maturity stage at harvest (Mattheis et al., 1995; Yahia et al., 1990). In a study where 'Gala' apples were stored in air for 1 month before being placed in CA storage, there was less CA retention of firmness and acidity (Boylston et al., 1994). Air-stored fruit emitted more volatiles and were preferred to CA stored fruit.

'Gala' apple has increased in popularity since its introduction from New Zealand in the late 1960s (Green and Autio, 1990; White, 1991). Consumer taste panels show strong preferences for 'Gala' over other cultivars (Green and Autio, 1990; Stebbins et al., 1994). However, hedonic ratings from consumer taste panels decreased for 'Gala' apples stored in air for $>60 \mathrm{~d}$ (Plotto et al., 1995; Stebbins et al., 1994). 'Gala' apples stored in CA maintain high levels of firmness and acidity (Drake, 1996), but reduction of volatile production reported for other apples also occurs for 'Gala' (Boylston et al., 1994; Mattheis et al., 1998; Plotto, 1998). The odor significance and relative olfactory power of volatile compounds emitted by 'Gala' have been determined previously using the gas chromatography (GC) and olfactometry technique, Osme (Plotto, 1998). Using this technique, trained panelists describe and rate the intensity of odoractive molecules as they elute from the GC during a chromatographic run. The Osme technique provides information on the odor activity of single compounds emitted by the apples. However, it gives an incomplete picture of the aroma perceived from the whole fruit. By using $O s m e$, it was found that compounds contributing to a fruity and apple-like odor in 'Gala' apples decreased significantly in CA storage 
and CA followed by RA (Plotto, 1998). The present study used DSA to measure aroma changes during storage of whole 'Gala' apples and related DSA results to Osme analysis. Changes in aroma and flavor perception due to cutting apples were also determined.

\section{Materials and Methods}

Plant Materials AND STORAge Conditions. 'Gala' apples from a commercial orchard near Chelan, Wash., were harvested 12 Sept. 1995. Apple maturity stage and homogeneity of the lots were assessed visually through the ground color (Plotto et al., 1995). Control (no long-term storage) apples were stored at $2{ }^{\circ} \mathrm{C}$ for 2 weeks until the first tests. Remaining fruit were stored at the U.S. Department of AgricultureAgricultural Research Service Tree Fruit Research Laboratory, Wenatchee, Wash., in either a conventional cold room [regular atmosphere (RA) fruit] or controlled atmosphere (CA) $0.14 \mathrm{~m}^{3}$ chambers. Fruit were held at $1^{\circ} \mathrm{C}$ for 10 and 20 weeks in either RA or CA with $\mathrm{O}_{2}$ and $\mathrm{CO}_{2}$ at $1 \mathrm{kPa}$. One additional storage treatment was 16 weeks in $\mathrm{CA}$ followed by 4 weeks in RA (CA/RA). After removal from storage, apples were shipped to Corvallis, Ore., stored at $2{ }^{\circ} \mathrm{C}$ for $5 \mathrm{~d}$, and then ripened at $20^{\circ} \mathrm{C}$ for $5 \mathrm{~d}$ before testing.

Panel training. Ten panelists participated in eight 1-h training sessions where descriptors, reference standards, and a standardized method of smelling and presenting the fruit were developed. All panelists were students and staff from Oregon State University, and $80 \%$ of them had participated previously in descriptive panels. 'Gala', 'Braeburn', and 'Fuji' apples were used to develop the descriptors as these cultivars represent a wide range of aromas and flavors. Most aroma descriptors were first suggested by the panel leader from previous reports (Daillant-Spinnler et al., 1996; Williams and Carter, 1977; Sensory Spectrum, Inc., Chatam, N.J., unpublished data), and from the descriptors used by three panelists smelling the effluents of 'Gala' apple headspace run through gas chromatography and olfactometry (Plotto, 1998). The final descriptors and their corresponding standards were chosen by the panelists after discussions during training. Panelists assigned standard intensity values by comparing aroma intensity found in the apples. Food grade chemical standards were obtained from Aldrich Flavors and Fragrances (Milwaukee, Wis.) and Fluka (Milwaukee, Wis.) (Table 1). They were diluted in odor-free, double distilled water (Milli-Q) to a concentration comparable to what was perceived in apples. Of the 13 descriptors chosen for aroma and 16 for flavor, 11 were identical (Table 1). Flavor was defined as the combined effect in the mouth of aromatics, basic tastes, and mouthfeel (Meilgaard et al., 1991). Each descriptor was rated using a 16-point intensity scale where $0=$ none, $7=$ moderate, and $15=$ extreme.

Training with fresh fruit during the time of harvest was finalized with four pretesting sessions using 'Gala' apples at different maturity stages to check for panelist performance. Before testing fruit after each 10-week storage period, a review session was organized where panelists compared 'Gala', 'Braeburn', and 'Fuji'.

Testing took place in individual booths located in a wellventilated room under daylight illumination. Panelists were provided with drinking water (Aqua-Cool, Portland, Ore.) and expectoration cups to cleanse their palates between samples.

Sample PRESENTATion. Six sets representing six replications of five 'Gala' apples per treatment were placed in single 4-L widemouth glass jars coded with a three digit random number, and left

Table 1. Attribute descriptors, ${ }^{\mathrm{z}}$ reference standards, ${ }^{\mathrm{y}}$ and their intensities for descriptive sensory analysis of 'Gala' apple aroma and flavor. Intensity rated on a 16-point category scale $(0=$ none, $7=$ moderate, and $15=$ extreme). All fruit samples were cut in pieces (peeled and cored) and placed in wine glasses covered with aluminum lids.

\begin{tabular}{|c|c|c|}
\hline Descriptor & Reference standard & Intensity \\
\hline \multicolumn{3}{|l|}{ Aroma and flavor } \\
\hline \multirow[t]{2}{*}{ Overall fruity } & $3.5 \mathrm{mg} \cdot \mathrm{L}^{-1}$ of butyl acetate, $0.8 \mathrm{mg} \cdot \mathrm{L}^{-1}$ of pentyl acetate, and $0.07 \mathrm{mg} \cdot \mathrm{L}^{-1}$ of ethyl-2-methylbutyrate in water & 3 \\
\hline & Very ripe 'Gala' & 13 \\
\hline Pear & 'Bartlett' & 13 \\
\hline Banana & Banana & 13 \\
\hline Watermelon & Watermelon & 8 \\
\hline Strawberry & Strawberry essential oil (Uncommon Scents, Eugene, Ore.) diluted to $100 \mathrm{mg} \cdot \mathrm{L}^{-1}$ & 8 \\
\hline Citrus & Citral: $25 \mathrm{mg} \cdot \mathrm{L}^{-1}$ & 10 \\
\hline Floral & 'Hawaiian blossom' (Uncommon Scents, Eugene, Ore.) diluted to $0.1 \mathrm{mg} \cdot \mathrm{L}^{-1}$ & 6 \\
\hline Anise & Anethole: $7.5 \mathrm{mg} \cdot \mathrm{L}^{-1}$ & 10 \\
\hline \multicolumn{3}{|l|}{ Overall vegetative $\mathrm{x}^{\mathrm{x}}$} \\
\hline Grassy & cis-3-Hexen-1-ol: $50 \mathrm{mg} \cdot \mathrm{L}^{-1}$ & 6 \\
\hline Green & trans-2-Hexenal: $25 \mathrm{mg} \cdot \mathrm{L}^{-1}$ & 8 \\
\hline Woody/stemmy & Hexanal: $9 \mathrm{mg} \cdot \mathrm{L}^{-1}$ & 8 \\
\hline Musty/dirty & Terpinen-4-ol: $25 \mathrm{mg} \cdot \mathrm{L}^{-1}$ & 10 \\
\hline Fermented & Apples fermented for 1 week in a tightly closed jar & 14 \\
\hline Anise flavor ${ }^{x}$ & Fennel & 14 \\
\hline Cooked fruit flavor ${ }^{x}$ & 'Welch's grape juice (Welch’s, Concord, Mass.) & 14 \\
\hline \multicolumn{3}{|l|}{ Taste } \\
\hline Sweet & Sucrose in water: 2,5 , and $10 \%$ w & $3,8,13$ \\
\hline Sour & Malic acid in water: $0.025,0.05$, and $0.08 \%^{\mathrm{w}}$ & $2,6,12$ \\
\hline Starchy & Raw jicama root peeled and cut into $1-\mathrm{cm}^{3}$ cubes & 13 \\
\hline Astringent & Alum in water: $0.05 \% \mathrm{v}$ & 14 \\
\hline
\end{tabular}

${ }^{\mathrm{z} O v e r a l l ~ v e g e t a t i v e ~ w a s ~ u s e d ~ a s ~ a ~ f l a v o r ~ a t t r i b u t e ~ f o r ~ g r a s s y, ~ g r e e n, ~ a n d ~ s t e m m y, ~ w h i c h ~ w e r e ~ n o t ~ d i s t i n g u i s h a b l e . ~}$

${ }^{y}$ All chemical standards were from Aldrich (Milwaukee, Wis.) except anethole, which was from Fluka Chemika (Milwaukee, Wis.). Standards were in $50 \mathrm{~mL}$ of odor-free double distilled water (Milli-Q) presented in 150-mL glass vials closed with Teflon lids.

${ }^{\mathrm{x}}$ Flavor descriptors only.

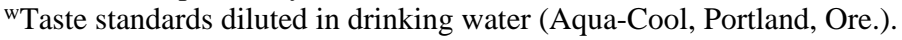


uncovered at room temperature for 1 to $6 \mathrm{~h}$ before testing. Two jars representing each storage treatment were presented to each panelist during each test session. Replications were randomized across panelists and the order of presentation A B or B A was balanced. Since there was no storage treatment for the control apples, two jars of the same batch were presented to the panelists. Apples stored 20 weeks in CA $\left(20 \mathrm{CA}_{1}\right)$ were compared with apples stored 20 weeks in air (20 RA) in one sitting, and another 30 apples of the same batch stored 20 weeks in $\mathrm{CA}\left(20 \mathrm{CA}_{2}\right)$ was compared with apples stored 16 weeks in CA followed by 4 weeks in air (CA/RA). Upon their arrival, panelists covered the jars with aluminum lids to allow volatile compounds to accumulate for 5 to $10 \mathrm{~min}$ while they reviewed reference standards. Panelists then opened the jar lids, smelled and rated external aroma (EA) of the apples. All the aroma descriptors were rated at once for each jar. Panelists were not allowed to compare between the two jars. After rating EA, panelists took one fruit of each treatment, cut it in half, cut one half into $2-\mathrm{cm}^{3}$ pieces with peel, placed the pieces in a wine glass labeled with the same three-digit number as the corresponding jar, and covered the glass with an aluminum lid. After $1 \mathrm{~min}$, cut fruit were rated for internal aroma (IA) using the same descriptors as for EA. The other half of the apple was set aside to evaluate flavor by mouth. After reviewing the taste standards, panelists removed $\approx 1 \mathrm{~cm}$ on each side of the cut apple to eliminate oxidized tissue. The top, bottom, and the core of the wedge were also removed to avoid taste differences between those portions of the fruit (Dever and Cliff, 1995). Panelists tasted the middle 2- $\mathrm{cm}^{3}$ section of apple with peel. Panelists evaluated each storage treatment for a total of six times (six replications) over a period of $3 \mathrm{~d}$, with two replications per day.

INSTRUMENTAL MEASUREMENTS. Apple headspace was sampled from whole apples (five fruit, $\approx 1 \mathrm{~kg}$ ) placed in 4 -L wide-mouth glass jars in a dynamic flow-through system with an airflow of 200 $\mathrm{mL} \cdot \mathrm{min}^{-1}$. Volatile compounds were trapped on activated charcoal during $24 \mathrm{~h}$ and later eluted with carbon disulfide. Volatile compound analysis and Osme are fully described in Plotto (1998).

About two-quarter sections cut longitudinally were taken on opposite sides of 20 'Gala' apples. Samples were juiced and soluble solids concentration was measured with an Auto Abbe electronic refractometer (Leica, Inc., Buffalo, N.Y.). Ten milliliters of juice was titrated with $0.1 \mathrm{~mol} \cdot \mathrm{L}^{-1} \mathrm{NaOH}$ to $\mathrm{pH} 8.2$ for titratable acidity (TA) measurements (Metrohm AG, Herisau, Switzerland). Juice $\mathrm{pH}$ was recorded before titration.

Statistical ANALYSES. Panelists' performances were evaluated through individual analyses of variance (ANOVA) during training and after each removal from storage. If $P<0.05$, showing a replication effect for an individual panelist, he or she was asked to pay attention to that specific attribute and use the standard more carefully. Differences between storage treatments (RA versus CA) were analyzed for each storage time and for each descriptor using the general linear model (GLM) procedure with a random statement for panelists, replication, and any interaction effect containing either panelist or replication. The model was treatment $=$ panelist replication panelist $\times$ replication treatment panelist $\times$ treatment. Only significant results at $P<0.05$ are discussed.

Principal components analysis (PCA) was performed on all taste sessions pooled into one data set. PCA was performed using a factor analysis with the principal component method (SAS Inst. Inc., 1988) on the covariance matrix of the residuals of a GLM where panelist was the main effect. The GLM residuals were used as a standardizing method to minimize the variability due to panelists using different parts of the scale (Piggot and Sharman, 1986). Factor scores for each principal component were analyzed using ANOVA. Average scores for storage treatments were plotted in the dimensions of the first two principal components (PC). In this plot, descriptors were represented as vectors. Vector angles reflected descriptor correlations with each other, and vector magnitude reflected the relative contribution to each $\mathrm{PC}$.

Instrumental data were analyzed for storage effect using oneway ANOVA. Sample means were separated with the LSD test. All statistical analyses were performed using SAS statistical software, version 6.12 (SAS Institute, Inc., 1988).

\section{Results}

DESCRIPTIVE SENSORY ANALYSIS. Differences between RA and CA storage increased with storage duration for overall fruity, pear,

Table 2. Descriptive profile of external aroma (EA) of 'Gala' apples stored for 2, 10, and 20 weeks in regular atmosphere (RA), controlled atmosphere (CA) $\left(1 \mathrm{kPaO}_{2}, 1 \mathrm{kPa} \mathrm{CO}\right)$, and 16 weeks in $\mathrm{CA}$ followed by 4 weeks in RA (CA/RA). Ratings are on a 16-point category scale $(0=$ none, 15 $=$ extreme).

\begin{tabular}{|c|c|c|c|c|c|c|c|}
\hline \multirow[b]{3}{*}{ Attribute } & \multicolumn{7}{|c|}{ Time (weeks) and type of storage } \\
\hline & \multirow{2}{*}{$\begin{array}{c}2 \text { (Control) } \\
\text { RA }\end{array}$} & \multicolumn{2}{|c|}{10} & \multicolumn{2}{|c|}{$20^{z}$} & \multicolumn{2}{|c|}{$20^{z}$} \\
\hline & & RA & $\mathrm{CA}$ & RA & $\mathrm{CA}_{1}$ & $\mathrm{CA} / \mathrm{RA}$ & $\mathrm{CA}_{2}$ \\
\hline Overall fruity & 8.27 & 9.02 & $6.92^{* * *}$ & 9.48 & $6.25^{* * *}$ & 7.25 & $6.38^{*}$ \\
\hline Pear & 5.17 & 5.70 & $3.95^{* * *}$ & 6.03 & $3.62^{* * * *}$ & 4.38 & 3.80 \\
\hline Banana & 3.02 & 2.82 & $1.72^{*}$ & 2.80 & $1.30^{*}$ & 2.22 & $1.62^{*}$ \\
\hline Watermelon & 1.47 & 1.58 & 1.50 & 1.48 & 1.28 & 1.32 & 1.17 \\
\hline Strawberry & 1.65 & 2.32 & $1.68^{*}$ & 2.38 & $1.47^{*}$ & 1.70 & 1.70 \\
\hline Citrus & 1.90 & 2.17 & 1.70 & 1.92 & 1.62 & 1.85 & 1.57 \\
\hline Floral & 3.70 & 4.32 & $3.10^{* *}$ & 4.27 & $2.23^{* * * *}$ & 3.38 & $2.67^{* *}$ \\
\hline Anise & 0.43 & 0.88 & 0.68 & 1.48 & 0.50 & 1.08 & $0.68^{*}$ \\
\hline Grassy & 0.90 & 1.35 & 1.43 & 1.35 & 1.52 & 1.27 & 1.22 \\
\hline Green & 2.90 & 2.22 & 1.85 & 1.73 & 1.92 & 1.83 & 1.50 \\
\hline Stemmy & 1.73 & 1.62 & 1.85 & 1.57 & 2.13 & 1.52 & 1.73 \\
\hline Musty & 0.90 & 0.83 & 0.73 & 0.68 & $1.20^{*}$ & 1.00 & 1.42 \\
\hline Fermented & 0.23 & 0.43 & 0.21 & 1.07 & 0.98 & 0.25 & 0.47 \\
\hline
\end{tabular}

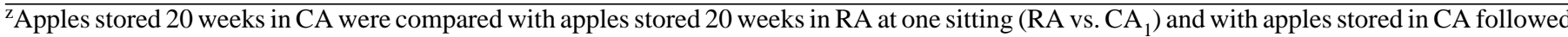
by RA at another sitting (CA/RA vs. $\mathrm{CA}_{2}$ ).

${ }^{*}, * *, * * *$ Significant at $P<0.05,0.01$, or 0.001 , respectively. Significance between two types of storage (RA vs. CA) within one storage time. 
Table 3. Descriptive profile of internal aroma (IA) of 'Gala' apples stored for 2, 10, and 20 weeks in regular atmosphere (RA), controlled atmosphere (CA) $(1 \mathrm{kPa} \mathrm{O}, 1 \mathrm{kPa} \mathrm{CO})$, and 16 weeks in CA followed by 4 weeks in RA (CA/RA). Ratings are on a 16-point category scale $(0=$ none, 15 $=$ extreme).

\begin{tabular}{|c|c|c|c|c|c|c|c|}
\hline \multirow[b]{3}{*}{ Attribute } & \multicolumn{7}{|c|}{ Time (weeks) and type of storage } \\
\hline & \multirow{2}{*}{$\begin{array}{c}\text { (Control) } \\
\text { RA } \\
\end{array}$} & \multicolumn{2}{|c|}{10} & \multicolumn{2}{|c|}{$20^{2}$} & \multicolumn{2}{|c|}{$20^{2}$} \\
\hline & & RA & $\mathrm{CA}$ & RA & $\mathrm{CA}_{1}$ & $\mathrm{CA} / \mathrm{RA}$ & $\mathrm{CA}_{2}$ \\
\hline Overall fruity & 7.65 & 8.30 & $5.93^{* * *}$ & 8.63 & $5.10^{* * * *}$ & 5.13 & 5.35 \\
\hline Pear & 4.87 & 5.57 & $3.67^{* *}$ & 5.80 & $2.68^{* * *}$ & 2.82 & 3.02 \\
\hline Banana & 2.63 & 2.52 & $1.00^{* *}$ & 3.10 & $1.02^{* *}$ & 1.10 & 1.13 \\
\hline Watermelon & 1.45 & 1.77 & 1.90 & 1.57 & 1.50 & 1.30 & 1.30 \\
\hline Strawberry & 1.22 & 1.50 & $1.06^{* *}$ & 1.48 & $1.00^{*}$ & 1.03 & 0.98 \\
\hline Citrus & 1.95 & 2.10 & 2.58 & 1.88 & 2.78 & 2.45 & 2.50 \\
\hline Floral & 3.55 & 3.48 & $2.10^{* *}$ & 3.52 & $1.53^{* *}$ & 1.95 & 2.02 \\
\hline Anise & 0.27 & 0.70 & $0.28^{*}$ & 1.07 & $0.38^{* * *}$ & 0.55 & 0.52 \\
\hline Grassy & 1.43 & 1.30 & $1.97^{*}$ & 1.30 & 2.27 & 1.75 & 1.65 \\
\hline Green & 3.72 & 2.65 & 3.10 & 2.02 & 2.88 & 2.47 & 2.70 \\
\hline Stemmy & 2.27 & 1.75 & 2.58 & 1.52 & $2.43^{* *}$ & 2.57 & 2.40 \\
\hline Musty & 0.78 & 0.88 & 1.17 & 0.92 & 1.38 & 2.10 & 2.17 \\
\hline Fermented & 0.32 & 0.52 & 0.98 & 0.97 & 1.35 & 0.77 & 0.97 \\
\hline
\end{tabular}

${ }^{\mathrm{z} A p p l e s ~ s t o r e d ~} 20$ weeks in CA were compared with apples stored 20 weeks in RA at one sitting (RA vs. CA $)$ and with apples stored in CA followed by RA at another sitting (CA/RA vs. $\left.\mathrm{CA}_{2}\right)$.

$*, * *, * * *$ Significant at $P<0.05,0.01$, or 0.001 , respectively. Significance between two types of storage (RA vs. CA) within one storage time.

banana, strawberry, and floral EA descriptors (Table 2). All fruity and floral characters decreased in CA storage. Fruity, banana, and floral aroma were greater in the CA/RA than in the CA treatments, but not as great as in the RA treatment. A stronger musty note in $\mathrm{CA}$ fruit was detected after 20 weeks storage.

Differences between CA and RA were found for overall fruity, pear, banana, strawberry, and floral aroma of cut fruit (Table 3). Intensity ratings were within the same ranges or slightly less compared with EA. The grassy and stemmy characters were perceived lower and anise higher for RA than CA-stored fruit. There were no significant differences for any IA descriptors between CA and CA/RA fruit.
Sweetness ratings decreased for CA fruit, and sourness decreased in RA during storage (Table 4). Astringent character was rated higher for CA apples. Similar to the aroma characters, flavor ratings for overall fruity, pear, banana, strawberry, and floral decreased after CA storage. The ratings given to citrus and overall vegetative flavor notes were higher in CA fruit, and the cooked fruit character was higher in RA fruit. Similar to internal aroma, there were no differences between CA and CA/RA fruit after 20 weeks for any flavor descriptor.

Principal COMPONENTS analysis. The first principal component (PC 1) explained $38 \%, 42 \%$, and $38 \%$ of the data set variation for EA, IA, and flavor, respectively (Fig. 1). PC 1 was explained by

Table 4. Descriptive profile of flavor of 'Gala' apples stored for 2, 10 and 20, weeks in regular atmosphere (RA), controlled atmosphere (CA) (1 $\left.\mathrm{kPa} \mathrm{O}_{2}, 1 \mathrm{kPa} \mathrm{CO}_{2}\right)$, and 16 weeks in CA followed by 4 weeks in RA (CA/RA). Ratings are on a 16-point category scale $(0=$ none, $15=$ extreme).

\begin{tabular}{|c|c|c|c|c|c|c|c|}
\hline \multirow[b]{3}{*}{ Attribute } & \multicolumn{7}{|c|}{ Time (weeks) and type of storage } \\
\hline & \multirow{2}{*}{$\begin{array}{c}2 \text { (Control) } \\
\text { RA }\end{array}$} & \multicolumn{2}{|c|}{10} & \multicolumn{2}{|c|}{$20^{z}$} & \multicolumn{2}{|c|}{$20^{z}$} \\
\hline & & RA & $\mathrm{CA}$ & RA & $\mathrm{CA}_{1}$ & $\mathrm{CA} / \mathrm{RA}$ & $\mathrm{CA}_{2}$ \\
\hline Sweet & 8.05 & 8.80 & $6.88^{* * * *}$ & 8.85 & $6.15^{* *}$ & 7.35 & 7.22 \\
\hline Sour & 5.18 & 4.03 & 5.23 & 3.58 & $6.75^{* * * *}$ & 5.25 & 5.58 \\
\hline Starchy & 1.93 & 1.85 & 3.02 & 2.20 & 2.97 & 3.02 & 3.02 \\
\hline Astringent & 1.07 & 0.60 & $1.55^{*}$ & 0.98 & $2.13^{* *}$ & 1.80 & 1.87 \\
\hline Overall fruity & 7.50 & 8.46 & $6.12^{*}$ & 8.40 & $5.78^{* * *}$ & 6.42 & 6.30 \\
\hline Pear & 4.67 & 4.97 & $3.17^{*}$ & 5.90 & $3.10^{* *}$ & 2.97 & 3.22 \\
\hline Banana & 2.30 & 2.22 & $0.87^{* *}$ & 2.65 & $0.78^{* *}$ & 1.20 & 0.93 \\
\hline Watermelon & 1.75 & 1.37 & 1.73 & 1.57 & 1.75 & 1.57 & 1.83 \\
\hline Strawberry & 1.00 & 1.25 & $0.70^{*}$ & 1.27 & 1.20 & 1.20 & 1.05 \\
\hline Citrus & 2.38 & 2.15 & 2.97 & 1.48 & $3.37^{* * *}$ & 2.63 & 2.80 \\
\hline Floral & 3.58 & 3.72 & $2.88^{*}$ & 3.70 & $2.33^{*}$ & 2.75 & 2.45 \\
\hline Anise & 1.28 & 0.87 & 0.62 & 1.27 & 0.50 & 0.50 & 0.75 \\
\hline Cooked & 1.33 & 2.90 & $1.15^{*}$ & 3.17 & $1.33^{* * *}$ & 1.57 & 1.55 \\
\hline Vegetative & 3.62 & 2.57 & $4.58^{* * *}$ & 2.68 & $4.90^{* * * *}$ & 4.23 & 4.18 \\
\hline Musty & 0.38 & 0.67 & 0.58 & 0.92 & 1.00 & 0.77 & 0.57 \\
\hline Fermented & 0.20 & 0.50 & 0.13 & 0.92 & 1.83 & 0.12 & 0.17 \\
\hline
\end{tabular}

${ }^{\mathrm{z}}$ Apples stored 20 weeks in CA were compared with apples stored 20 weeks in RA at one sitting (RA vs. CA 1 ) and with apples stored in CA followed by RA at another sitting (CA/RA vs. $\left.\mathrm{CA}_{2}\right)$.

${ }^{*}, * *, * * *$ Significant at $P<0.05,0.01$, or 0.001 , respectively. Significance between two types of storage (RA vs. CA) within one storage time. 
overall fruity, pear, banana, and floral descriptors for EA, IA, and flavor, and also by sweet for flavor. Storage types were separated $(P$ $<0.001)$ on the first principle component axis with positive scores for RA fruit (including the controls) and negative scores for CA fruit.

Fig. 1. Principal components analysis plots for external aroma, internal aroma, and flavor of 'Gala' apples stored for 10 or 20 weeks in regular atmosphere (RA), controlled atmosphere (CA) $\left(1 \mathrm{kPa} \mathrm{O}_{2}, 1 \mathrm{kPa} \mathrm{CO}\right)$, and 16 weeks in CA followed by 4 weeks in RA (CA/RA). Principal components loadings are determined by the vector lengths for each sensory attribute. All vectors start at the origin. Their directions and magnitudes (loadings) are represented by the figure diamonds. Scores for storage treatments are drawn in circles; $20 \mathrm{CA}_{1}$ and $20 \mathrm{CA}_{2}$ were 20 weeks in CA compared with 20 weeks in RA and CA/RA, respectively. Control apples were stored 2 weeks in RA.

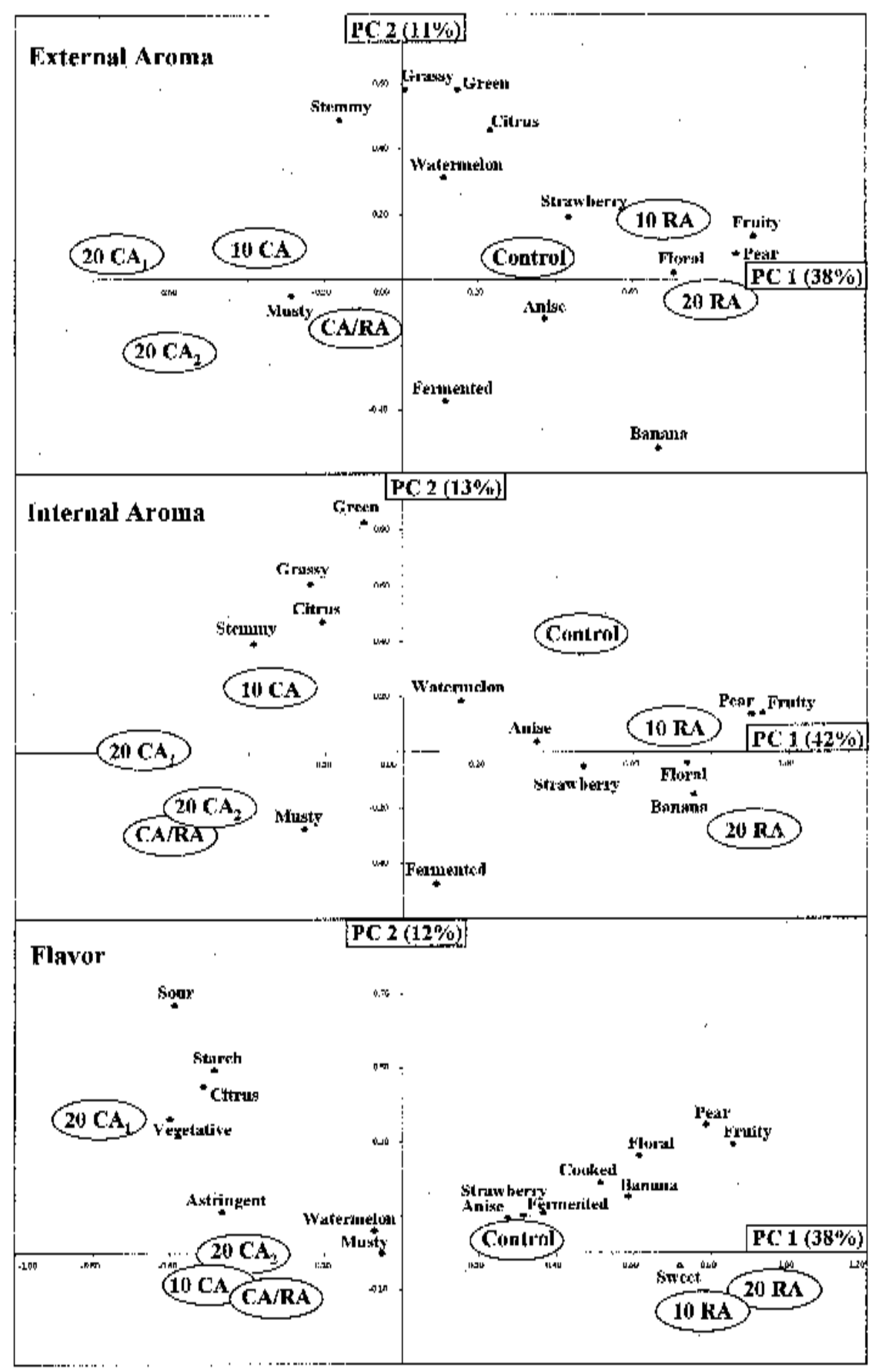

Treatment scores for PC 1 showed differences for fruity descriptors between RA and CA fruit increased with storage time.

The second principal component (PC 2) explained 11\%, 13\%, and $12 \%$ of the total variation for EA, IA, and flavor, respectively (Fig. 1). Treatment differences in the second principal component axis were only significant $(P<0.001)$ for IA. PC 2 was explained on the positive side by the descriptors green, grassy, stemmy, and citrus for EA and IA, and sour, starch, citrus, and overall vegetative for flavor. The fermented descriptor had a high negative loading on PC 2 for EA and IA, and banana also had a high negative loading on PC 2 of EA. The control sample had the highest PC 2 score for IA evaluation. Also, IA of CA fruit had slightly higher scores compared with RA fruit within a storage time. Fruit stored for 20 weeks in $\mathrm{CA}\left(20 \mathrm{CA}_{1}\right)$ had the highest PC 2 score for flavor when compared with RA fruit (20 RA).

INSTRUMENTAL ANALYSIS. Total volatileesters emitted by whole 'Gala' apples decreased significantly in CA storage (Table 5). The highest $\mathrm{pH}$ and lowest $\mathrm{TA}$ were recorded for fruit stored 20 weeks in RA. CA stored fruit had the lowest $\mathrm{pH}$ and highest TA as in the control. Fruit stored 10 weeks in CA had the highest SSC level, followed by the control.

\section{Discussion}

RELATIONSHIP BETWEEN AROMA DESCRIPTORS AND VOLATILE COMPOUNDS EMITTED BY 'GALA' APPLES. The decrease in perceived fruitiness of CA apples by DSA is in agreement with a decrease in volatile production as shown by the gas chromatography results (Table 5). Control fruit had the highest production of volatile esters. Despite training of the panelists and use of reference standards, results showed $R A$ versus $C A$ differences but did not demonstrate storage time changes. A contrast effect (Meilgaard et al., 1991) appeared for the fruit tasted after 20 weeks; fruit stored 20 weeks in CA and compared with RA (20 RA versus $20 \mathrm{CA}_{1}$ ) had lower PC 1 scores than when compared with $\mathrm{CA} / \mathrm{RA}$ fruit (CA/ RA versus $20 \mathrm{CA}_{2}$ ) (Fig. 1). Ratings for fruity characters for the control apples were equal to or lower compared with values for RA fruit after 10 and 20 weeks storage (Tables 2, 3, and 4). PCA scores for controls were also lower than scores after 10 and 20 weeks in RA for the fruity, pear, banana, and floral component (PC 1, Fig. 1). The PCA plots for DSA were nevertheless similar to published volatile analysis PCA plots where CA and RA stored fruit were separated on the first principal component, which was qualified by volatile esters with a fruity odor (Plotto, 1998).

The overall fruity attribute could be explained by volatile esters that had been demonstrated by $O$ sme analysis to have fruity and apple-like odors (Plotto, 1998). Hexyl acetate, butyl acetate, and 2-methylbutyl acetate have been identified to be primarily respon- 
Table 5. 'Gala' total volatile esters, pH, titratable acidity (TA), and soluble solids content (SSC) in regular (RA) and controlled atmosphere storage (CA).

\begin{tabular}{|c|c|c|c|c|c|c|}
\hline \multirow[b]{3}{*}{ Parameter } & \multicolumn{3}{|c|}{ RA } & \multicolumn{3}{|c|}{$\mathrm{CA}$} \\
\hline & \multicolumn{3}{|c|}{ Storage duration (weeks) } & \multicolumn{3}{|c|}{ Storage duration (weeks) } \\
\hline & 2 & 10 & 20 & 10 & $16^{\mathrm{z}}$ & 20 \\
\hline Total esters $\left(\mathrm{ng} \cdot \mathrm{L}^{-1}\right)^{\mathrm{y}}$ & $17343 \mathrm{a}^{\mathrm{x}}$ & $11665 \mathrm{bc}$ & $14584 \mathrm{ab}$ & $8033 \mathrm{~cd}$ & $3841 \mathrm{de}$ & $932 \mathrm{e}$ \\
\hline $\mathrm{pH}$ & $3.88 \mathrm{~b}$ & $3.85 \mathrm{c}$ & $4.00 \mathrm{a}$ & $3.83 \mathrm{c}$ & $3.79 \mathrm{~d}$ & $3.78 \mathrm{~d}$ \\
\hline TA $(\% \text { malic acid })^{\mathrm{w}}$ & $0.37 \mathrm{~b}$ & $0.33 \mathrm{c}$ & $0.26 \mathrm{~d}$ & $0.39 \mathrm{a}$ & $0.36 \mathrm{~b}$ & $0.36 \mathrm{~b}$ \\
\hline $\operatorname{SSC}\left({ }^{\circ} \mathrm{Brix}\right)^{\mathrm{w}}$ & $14.0 \mathrm{~b}$ & $13.3 \mathrm{c}$ & $13.1 \mathrm{c}$ & $14.5 \mathrm{a}$ & $13.8 \mathrm{~b}$ & $13.2 \mathrm{c}$ \\
\hline
\end{tabular}

${ }^{\mathrm{z}} 16$ weeks in CA was followed by 4 weeks in RA.

yValues are means of four 1-kg replications of dynamic headspace sampling.

${ }^{x}$ Mean separation within rows (entire row) by the Fisher's protected LSD test, $P<0.05$.

wValues are means of 20 apples.

sible for apple aroma in several cultivars (Paillard, 1975; Williams and Knee, 1977) including 'Gala' (Young et al., 1996). Hexyl acetate is also an important contributor to pear aroma (Suwanagul, 1996). The descriptor given to hexyl acetate odor in Osme analysis was "Gala, ripe apple, pear" (Plotto, 1998), and when presented to panelists diluted in distilled water, it had an aroma similar to apple (Plotto et al., 1998). Therefore, hexyl acetate was probably the volatile contributing the most to the overall fruity and pear attributes. 2-methylbutyl acetate was suggested to be related to banana descriptors in DSA of 'Cox's Orange Pippin' (Williams and Knee, 1977). However, it did not have a banana descriptor in Osme analysis, and no other compound had that descriptor (Plotto, 1998).

The floral descriptor contributed significantly to PC 1 and separated CA and RA-stored apples (Fig. 1). However, only one unknown peak had a floral descriptor in Osme analysis and it was perceived with a low intensity (Plotto, 1998). Therefore, several compounds may contribute collectively to the floral note of 'Gala' apple.

The strawberry descriptor intensity decreased slightly in CA storage, and it did not contribute significantly to PC loadings. When smelled individually from the gas chromatograph effluents, methyl 2-methylbutyrate, ethyl 2-methylbutyrate and propyl 2methylbutyrate had distinct sweet and strawberry-like aromas (Plotto, 1998). These methylbutyrate esters may be important for the general fruity and sweet aroma of 'Gala', but are not distinguished from the overall apple aroma.

Watermelon was chosen as a descriptor in this study because a compound with a watermelon odor was perceived with a high intensity in Osme analysis (Plotto, 1998). However, the watermelon descriptor was not highly rated and was not perceived by some panelists in the descriptive analysis. The watermelon compound perceived in Osme analysis was probably blended in other fruity notes, or it might also contribute to the floral character.

The musty note perceived in CA fruit (Table 2) could be due to a compound with a garlic odor (Plotto, 1998). This unknown compound perceived only in CA fruit was also given low ratings in Osme analysis. However, because the compound had a distinct odor compared with the fruity esters, it could be perceived by the descriptive panel.

EFFECT OF COMBINED ATMOSPHERES ON AROMA PERCEPTION. The inhibiting effect of CA storage on volatile production by apples is well documented (Yahia, 1994). A partial recovery of volatile production may occur when apples are placed in air or higher $\mathrm{O}_{2}$ levels for some weeks before removal from storage (Brackmann et al., 1993; Smith, 1984; Streif and Bangerth, 1988). Volatile compounds were emitted in larger amounts when 'Gala' apples stored in CA for 16 weeks were then placed in air for 4 weeks (Table 5). Differences were only perceived for whole fruit aroma by DSA
(Table 2). An increase in volatile production was not always observed in similar experiments (Mattheis et al., 1995; Yahia, 1991). The response may therefore depend on the cultivar, maturity stage at harvest, storage atmosphere combinations, and other cultural factors.

CUt Fruit AROMa AND Flavor. The aroma descriptors green, grassy, and stemmy, which were perceived as different odors, were not distinguishable when tasted. Therefore the more general term overall vegetative was used for the flavor descriptor. The green-like aroma descriptors had higher intensities in cut than in whole apples and were rated higher in CA than in RA fruit (Table 3). Likewise, the vegetative flavor descriptor decreased significantly in RA apples (Table 4). Compounds known to possess green apple-like odors are hexanal and trans-2-hexenal (Flath et al., 1967). Their production increases upon cutting or crushing fruit cells (Drawert et al., 1966). Fellman et al. (1993) found more hexanal in flesh of 'Rome' apples stored in $1 \mathrm{kPa} \mathrm{O}_{2}$ compared with fruit stored in air. In our study, headspace analysis that we used to sample free volatiles emitted by whole apples could not reflect the amount actually present in the fruit. Nevertheless, higher amounts of hexanal and trans-2-hexenal may be present in larger amounts in CA fruit because those fruit do not use their reserves by respiration. Other findings report opposite results regarding hexanal concentrations emitted by CA stored apples (Mattheis et al., 1995; 1998; Yahia et al., 1990). It is then possible the green-like attributes were perceived with higher intensities in 'Gala' apples stored in CA because the fruity attributes were not as strong.

The citrus attribute was correlated with green, grassy, and stemmy descriptors in the PCA of EA and IA (Fig. 1). RA fruit had a lower IA citrus rating after 20 weeks compared with CA fruit (Table 3), and this difference was also detected in the flavor profile (Table 4). Odor of aldehydes such as citral, octanal, and decanal are part of citrus aroma (Bazemore, 1995; Young, 1997). Citral has not been reported in apples (Paillard, 1990), but octanal and decanal are present in 'Gala' apple headspace (Mattheis et al., 1998). Those two aldehydes have low odor thresholds: $0.70 \mu \mathrm{g} \cdot \mathrm{L}^{-1}$ and $0.10 \mu \mathrm{g} \cdot \mathrm{L}^{-1}$ for octanal and decanal, respectively (Guadagni et al., 1963). However, they were not found in samples analyzed by Osme because of the volatile isolation technique used (Plotto, 1998). Therefore, their contribution to apple aroma is not clear. A decrease in citrus aroma flavor in RA fruit could be due to the lower perceived sourness from decreasing total acidity.

Cooked fruit flavor was rated higher in RA fruit (Table 4). It is possible $\beta$-damascenone contributes to cooked fruit flavor because 'Welch's (Welch's, Concord, Mass.) grape juice was used as a standard for this descriptor and $\beta$-damascenone by itself has a grapejuice odor (Plotto, 1998). B-Damascenone is a glycosidically bound compound (Buttery et al., 1990a) released in the mouth upon cellular 
disruption. It is present in apples (Cunningham et al., 1986; Schreier et al., 1978) and has a low odor threshold: $0.002 \mu \mathrm{g} \cdot \mathrm{L}^{-1}$ (Buttery et al., 1990b).

RELATION BETWEEN TASTE DESCRIPTORS AND INSTRUMENTAL MEASUREMENTS. Sourness differences between CA and RA stored fruit corresponded to the measured differences in $\mathrm{pH}$ and in titratable acidity (TA) (Table 5). The decrease of malic acid from fruit respiration in air storage and a reduced acid loss in CA are well documented (Anderson and Penney, 1973; Chen et al., 1985; Smock, 1979). Changes in titratable acidity in apples are usually perceived by trained and untrained panelists (Anderson and Penney, 1973; Gorin, 1973; Plotto et al., 1997; Visser et al., 1968; Watada et al., 1980; Williams and Langron, 1983).

Sweetness ratings were significantly lower for CA than for RAstored fruit (Table 4). However, the sensory difference between treatments was not reflected by the refractometer measurements (Table 5). Refractive index (Dever and Cliff, 1995; Knee and Smith, 1989; Plotto et al., 1997) and total sugar content (Rouchaud et al. 1985) are poor predictors for perceived sweetness in apples. The difference of $1{ }^{\circ}$ Brix between two levels of SSC found in apples is not enough to be perceived as sweetness differences. Differences between CA and RA fruit in perceived sweetness could be due in part to differences in perceived acidity as well as volatile esters with sweet odors. Watada et al. (1981) reported some contribution of volatile compounds to the sweetness and tartness ratings of 'Golden Delicious' and 'York Imperial' apples.

Astringency was higher in CA than in RA-stored apples (Table 4). In a DSA study of five apple cultivars during storage, Watada et al. (1980) found a decrease in astringency after RA storage for all cultivars tested. Besides polyphenolic compounds which are usually responsible for that feeling in the mouth (Mazza and Miniati, 1993), some acids were demonstrated to induce astringency: malic acid at $0.037 \%$ or $0.075 \%(\mathrm{w} / \mathrm{v})$ in water induced stronger intensity responses for astringency than for sourness (Straub, 1989). Therefore, the higher astringent ratings for CA-stored fruit could also have been due to higher malic acid content of the fruit.

In summary, descriptive sensory analysis of 'Gala' apples showed a significant decrease in fruity (pear-, banana-, and strawberry-like) and floral descriptors for EA, IA, and flavor of CA fruit. Green, vegetative, and citrus descriptors were perceived with higher intensities in cut fruit aroma and flavor. The higher ratings for those descriptors in CA fruit may have been due to the decrease in fruity aromas.

The combination of DSA, GC, and Osme analyses explained earlier findings from a consumer panel with 'Gala' apples (Boylston et al., 1994). In that study, the decrease in total volatiles resulted in a lower acceptance of delayed CA 'Gala' apples with the same firmness values as RA fruit. On the other hand, firmer apples are usually preferred (Williams, 1979). Transferring apples to air storage for 4 weeks following 16 weeks CA improved volatile production. However, the increase in volatile esters was not perceived as increased fruity flavor in our panel.

Use of CA technology allows maintenance of quality and freshness of apples from harvest compared with air storage. However, the complexity of the effects of physical and chemical stimuli on human taste buds and olfactory receptors require sensory analysis following CA experiments to evaluate fruit eating quality.

\section{Literature Cited}

Anderson, R.E. and R.W. Penney. 1973. Quality of 'Stayman Winesap' apples stored in air, controlled atmospheres, or controlled atmospheres followed by storage in air. HortScience 8:507-508.
Bazemore, R.A. 1995. Osme and sensory analysis of aqueous orange essence. MS thesis, Oregon State Univ., Corvallis.

Boylston, T.D., E.M. Kupferman, J.D. Foss, and C. Buering. 1994. Sensory quality of Gala apples as influenced by controlled and regular atmosphere storage. J. Food Quality 17:477-494.

Brackmann, A., J. Streif, and F. Bangerth. 1993. Relationship between a reduced aroma production and lipid metabolism of apples after long-term controlled-atmosphere storage. J. Amer. Soc. Hort. Sci. 118:243-247.

Buttery, R.G., G. Takeoka, R. Teranishi, and L.C. Ling. 1990a. Tomato aroma components: Identification of glycoside hydrolysis volatiles. J. Agr. Food Chem. 38:2050-2053.

Buttery, R.G., R. Teranishi, L.C. Ling, and J.G. Turnbaugh. 1990b. Quantitative and sensory studies on tomato paste volatiles. J. Agr. Food Chem. 38:336-340.

Chen, P.M., K.L. Olsen, and M. Meheriuk. 1985. Effect of low-oxygen atmosphere on storage scald and quality preservation of 'Delicious' apples. J. Amer. Soc. Hort. Sci. 110:16-20.

Cunningham, D.G., T.E. Acree, J. Barnard, R.M. Butts, and P.A. Braell. 1986. Charm analysis of apple volatiles. Food Chem. 19:137-147.

Daillant-Spinnler, B., H.J.H. MacFie, P.K. Beyts, and D. Hedderley. 1996. Relationships between perceived sensory properties and major preference directions of 12 varieties of apples from the Southern Hemisphere. Food Quality Preference 7:113-126.

Dever, M.C. and M.A. Cliff. 1995. Analysis of variation and multivariate relationships among analytical and sensory characteristics in whole apple evaluation. J. Sci. Food Agr. 69:329-338.

Drake, S.R. 1996. Controlled atmosphere of apples with pears. Wash. State Univ. Tree Fruit Postharvest J. 8(1):12-15.

Drawert, F., W. Heimann, R. Emberger, and R. Tressl. 1966. Über die biogenese von aromastoffen bei pflanzen und früchten. II. Enzymatische bildung von hexen (2) al (1), hexanal und deren vorstufen. Liebigs Ann. Chem. 694:200-208.

Fellman, J.K., D.S. Mattinson, B.C. Bostick, J.P. Mattheis, and M.E. Patterson. 1993. Ester biosynthesis in 'Rome' apples subjected to lowoxygen atmospheres. Postharvest Biol. Technol. 3:201-214.

Flath, R.A., D.R. Black, D.G. Guadagni, W.H. McFadden, and T.H. Schultz. 1967. Identification and organoleptic evaluation of compounds in 'Delicious' apple essence. J. Agr. Food Chem. 15:29-35.

Gorin, N. 1973. Several compounds in Golden Delicious apples as possible parameters of acceptability. J. Agr. Food Chem. 21:670-673.

Green, D.W. and W.R. Autio. 1990. Comparison of ripening and fruit quality of 'Gala' and 'McIntosh' apples at harvest and following air storage. Fruit Var. J. 22:1-4.

Guadagni, D.G., R.G. Buttery, and S. Okano. 1963. Odour thresholds of some organic compounds associated with food flavours. J. Sci. Food Agr. 14:761-765.

Knee, M. and S.M. Smith. 1989. Variation in quality of apple fruits stored after harvest on different dates. J. Hort. Sci. 64:413-419.

Mattheis, J.P., D.A. Buchanan, and J.K. Fellman. 1995. Volatile compound production by Bisbee Delicious apples after sequential atmosphere storage. J. Agr. Food Chem. 43:194-199.

Mattheis, J.P., D.A. Buchanan, and J.K. Fellman. 1998. Volatile production by 'Royal Gala' apples following sequential atmosphere storage, $\mathrm{p}$. 201-206. In: R. Bieleski, W. Laing, and C. Clark (eds.). Postharvest 96. Acta Hort. 464.

Mazza, G. and E. Miniati. 1993. Anthocyanins in fruit, vegetables and grains. CRC Press, Boca Raton, Fla.

Meilgaard, M., G.V. Civille, and T. Carr. 1991. Sensory evaluation techniques. 2nd ed. CRC Press, Boca Raton, Fla.

Paillard, N.M.M. 1975. Comparaison de l'arôme de différentes variétés de pommes: relation entre les différences d'impressions olfactives et les aromagrammes. Lebensm.-Wiss. Technol. 8:34-37.

Paillard, N.M.M. 1990. The flavour of apples, pears and quinces, p. 1-41. In: I.D. Marton and A.J. MacLeod (eds.). Food flavours. Part C: The flavour of fruits. Elsevier, Amsterdam, The Netherlands.

Patterson, B.D., S.G.S. Hatfield, and M. Knee. 1974. Residual effects of controlled atmosphere storage on the production of volatile compounds by two varieties of apples. J. Sci. Food Agr. 25:843-849. 
Piggott, J.R. and K. Sharman. 1986. Methods to aid interpretation of multidimensional data, p. 181-232. In: J.R. Piggott (ed.). Statistical procedures in food research. Elsevier, London.

Plotto, A. 1998. Instrumental and sensory analysis of 'Gala' apple (Malus domestica Borkh.) aroma. $\mathrm{PhD}$ thesis, Oregon State Univ., Corvallis.

Plotto, A., A.N. Azarenko, J.P. Mattheis, and M.R. McDaniel. 1995. 'Gala', 'Braeburn' and 'Fuji' apples: Maturity indices and quality after storage. Fruit Var. J. 49:133-142.

Plotto, A., A.N. Azarenko, M.R. McDaniel, P.W. Crockett, and J.P. Mattheis. 1997. Eating quality of 'Gala' and 'Fuji' apples from multiple harvests and storage durations. HortScience 32:903-908.

Plotto, A., J.P. Mattheis, D.S. Lundahl, and M.R. McDaniel. 1998. Validation of gas chromatography olfactometry results for 'Gala' apples by evaluation of aroma-active compound mixtures, p. 290-302. In: C.J. Mussinan and M.J. Morello (eds.). Flavor analysis: Developments in isolation and characterization. Amer. Chem. Soc., Washington, D.C. Symp. Ser. 705.

Rouchaud, J., C. Moons, and J.A. Meyer. 1985. Cultivar differences in the influence of harvest date and cold storage on the free sugars and acids contents, and on the eating quality of apples. J. Hort. Sci. 60:291-296.

SAS Institute, Inc., 1988. SAS/STAT user's guide. release $6.03 \mathrm{ed}$. SAS Inst., Inc., Cary, N.C.

Schreier, P., F. Drawert, and M. Schmid. 1978. Changes in the composition of neutral volatile components during the production of apple brandy. J. Sci. Food. Agr. 29:728-736.

Smith, S.M. 1984. Improvement of aroma of Cox's Orange Pippin apples stored in low oxygen atmospheres. J. Hort. Sci. 59:515-522.

Smock, R.C. 1979. CA storage of fruits. Hort. Rev. 1:301-336.

Stebbins, R.L., A.A. Duncan, and C.O. Compton. 1994. Apple variety trial: 1988-94 progress report. Oregon State Univ. Ext. Serv., Corvallis.

Straub, A.M. 1989. Power function determination for sourness and timeintensity measurements of sourness and astringency for selected acids. MS thesis, Oregon State Univ., Corvallis.

Streif, J. and F. Bangerth. 1988. Production of volatile aroma substances by 'Golden Delicious' apple fruits after storage for various times in different $\mathrm{CO}_{2}$ and $\mathrm{O}_{2}$ concentrations. J. Hort. Sci. 63:193-199.

Suwanagul, A. 1996. Ripening pear flavor volatiles: Identification, biosyn- thesis and sensory perception. $\mathrm{PhD}$ thesis, Oregon State Univ., Corvallis.

Visser, T., A.A. Schaap, and D.P. De Vries. 1968. Acidity and sweetness in apple and pear. Euphytica 17:153-167.

Watada, A.E., J.A. Abbott, and R.E. Hardenburg. 1980. Sensory characteristic of apple fruit. J. Amer. Soc. Hort. Sci. 105:371-375.

Watada, A.E., J.A. Abbott, R.E. Hardenburg, and W. Lusby. 1981. Relationships of apple sensory attributes to headspace volatiles, soluble solids, and titratable acids. J. Amer. Soc. Hort. Sci. 106:130-132.

White, A.G. 1991. The 'Gala' apple. Fruit Var. J. 45:2-3.

Williams, A.A. 1979. The evaluation of flavour quality in fruits and fruit products, p. 287-305. In: D.G. Land and H.E. Nursten (eds.). Progress in flavour research. Applied Science, London.

Williams, A.A. 1981. Relating sensory aspects to quality, p. 17-33. In: P.W. Goodenough and R.K. Atkin (eds.). Quality in stored and processed vegetables and fruit. Academic Press, London.

Williams, A.A. and C.S. Carter. 1977. A language and procedure for the sensory assessment of Cox's Orange Pippin apples. J. Sci. Food Agr. 28:1090-1104.

Williams, A.A. and M. Knee. 1977. The flavour of Cox's Orange Pippin apples and its variation with storage. Ann. Appl. Biol. 87:127-131.

Williams, A.A. and S.P. Langron. 1983. Influence of different controlled atmospheres and post-storage temperatures on the acceptability of Cox's Orange Pippin and Suntan apples. J. Sci. Food Agr. 34:13751382.

Yahia, E.M. 1991. Production of some odor-active volatiles by 'McIntosh' apples following low-ethylene controlled-atmosphere storage. HortScience 26:1183-1185.

Yahia, E.M. 1994. Apple flavor. Hort. Rev. 16:197-234.

Yahia, E., F.W. Liu, and T.E. Acree. 1990. Changes of some odor-active volatiles in controlled atmosphere-stored apples. J. Food Qual. 13:185202.

Young, H., J.M. Gilbert, S.H. Murray, and R.D. Ball. 1996. Causal effects of aroma compounds on Royal Gala apple flavours. J. Sci. Food Agr. 71:329-336.

Young, S.L. 1997. Gas chromatography/olfactometry and descriptive analysis of cold-pressed lemon oil aroma. MS thesis, Oregon State Univ., Corvallis. 